\title{
Prologue: The Whole Body as an Immune System
}

\begin{abstract}
All body cells that express PRMs to sense MAMPs or DAMPs can be counted as cells of the innate immune defense system in the broader sense. As comprehensively reviewed elsewhere [1], we can divide them into groups of mobile/circulating innate immune cells (sometimes denoted in the literature as the real innate immune cells) and sessile/resident innate immune cells. This new insight into the plethora of body cells operating as PRM-bearing cells of the innate immune system has led to the modern definition of the term immunity, whereby the innate immune system can now be regarded as an organ of perception (compare Part II, Sect. 4.4). Besides others, this new notion also explains why the innate immune system is not only responsible for mounting destructive pro-inflammatory processes (mainly mediated by mobile PRM-expressing innate immune cells) but also for tissue-repairing and regenerative processes (mainly mediated by sessile PRM-expressing innate immune cells). In this Part III, a variety of cells acting in commission of the innate immune system are briefly highlighted by stressing those cell types which appear to be most important regarding the perspective of the book.
\end{abstract}

\section{Reference}

1. Land WG. Innate alloimmunity Part 1. Innate immunity and host defense. Baskent University, Ankara; Pabst Science Publishers, Lengerich. 2011. Available from: ISBN 978-3-89967-737-9 